\title{
ANALISIS TINDAK TUTUR DALAM NOVEL SURAT KECIL UNTUK TUHAN KARYA AGNES DAVONAR
}

\section{AN ANALYSIS OF SPEECH ACTIONS IN DAVONAR'S SMALL LETTER FOR GOD NOVEL}

\author{
Rosary Iriany ${ }^{1}$ \\ Universitas Pancasakti \\ Makassar $^{1}$ \\ email: \\ rosaryiriany2401@gmai \\ $\underline{1 . \mathrm{com}}$
}

IJI Publication p-ISSN: 2774-1907 e-ISSN: 2774-1915 Vol.1, No.1, pp.33-49, Nopember 2020

Unit Publikasi Ilmiah Intelektual Madani Indonesia
Abstrak: Penelitian ini bertujuan untuk mengetahui bagaimana tindak tutur kata lokusi, ilokusi, perlokusi dalam Novel Surat Kecil untuk Tuhan menggunakan pendekatan Stilistika. Penelitian ini tergolong dalam penenlitian kualitatif karena sesuai dengan objek dan tujuan yang ingin dicapai. Objek yang akan dikaji dalam penelitian ini adalah tindak tutur kata dalam novel Surat Kecil untuk Tuhan. Teknik yang digunakan dalam pengumpulan data adalah teknik baca, teknik simak, dan catat. Berdasarkan hasil penelitian dapat menyimpulkan bahwa tindak tutur lokusi paling mendominasi yaitu tindak tutur yang menyatakan sesuatu dalam kata. Kemudian, tindak tutur perlokusi yang gaya kepekaan batinnya (intunisi) menonjol. Selanjutnya, tindak tutur ilokusi yang merupakan tindak tutur yang biasanya diidentifikasikan kalimat performatif yang eksplisit. Tindak tutur ilokusi ini biasanya berkenaan dengan pemberian izin, mengucapkan terima kasih, menyuruh, dan menawarkan. Hal tersebut sangat relevan dengan kajian stilistika dan novel Surat Kecil untuk Tuhan karena dalam novel tersebut menceritakan tentang kisah seorang gadis yang terserang penyakit kanker. Gadis tersebut memiliki sifat yang tegas, kuat, tegar, dan penyabar. Juga menceritakan tentang pengorbanan seorang kakak untuk adiknya. Tentu saja dengan menggunakan kajian stilistika kita dapat mengetahui kepribadian dan hal-hal apa saja yang dialami dan dirasakan oleh tokoh Keke dalam novel Surat Kecil untuk Tuhan. Karya sastra merupakan bagian dari kehidupan manusia. Salah satu karya sastra yang berisi kisah hidup seorang penyair itu sendiri adalah novel yang berjudul Surat Kecil untuk Tuhan. Novel ini merupakan novel inspiratif karena memberikan gambaran kepada pembaca dalam memperjuangkan sebuah impian, kasih sayang keluarga, pengorbanan, kuat, tegar, dan pekerja keras.

Kata kunci : Tindak Tutur; Novel; Psikologi Sastra.

Abstract: This study aims to determine how the speech actions of locution, ilocution, and perlocution in novel Surat Kecil untuk Tuhan use the stylistic approach. This research applied qualitative research as it is in accordance with the object and objectives that would be achieved. The object to be studied in this research was the speech acts in the novel Surat Kecil untuk Tuhan. The techniques used in data collection were reading techniques, listening techniques, and writing notes. Based on the research results, the researcher concludes that the most dominant locution of speech acts are speech acts that state something in words. Then, a perlocutionary speech acts whose inners sensitivity (intunition)stands out. Furthermore, illocutionary speech acts, which are speech acts that are usually indentified with explicit performative sentences. These illocutinary speech actsusually involve giving permission, saying thanks, ordering, and offering. This is very relevant to stylistic studies and the novel Surat Kecil untuk Tuhan because the novel tells the story of a girl who is sticken with cancer. The girl has a firm, srtong, tough, and patient character. Also the novel tells about the sacrifice of a brother for his younger brother. Of course, by using stylistic studies, we find out what personality and tings the Keke's character experienced and felt in the novel Surat Kecil untuk Tuhan. Literary works are part of human life. One of literary works that contains the life story of a poet himself is a novel entitled A Small Latter to God (Surat Kecil untuk Tuhan). This noves is an inpirational novel because it provides an overview for readers in fighting for a dream, family love, sacrifice, being strong, tough, and hardworking.

Keywords: speech acts; novel; literature psychology.

\section{PENDAHULUAN}

Karya sastra merupakan hasil karya pemikiran kreatif dari pengarang yang dituangkan dalam sebuah cerita dengan menggunakan bahasa sebagai mediumnya. Karya sastra muncul dari perpaduan antara kenyataan sosial yang berada dalam lingkungan sekitar dengan kreativitas pengarang. Dengan membaca karya sastra pembaca diharapkan dapat belajar dan mendapatkan pengalaman tentang masalahmasalah yang ada dalam kehidupan nyata. Hal ini diperkuat oleh Damono (1984:1) karya sastra diciptakan oleh sastrawan untuk 
dinikmati, dipahami, dan dimanfaatkan oleh masyarakat.

Sastra dapat menampilkan gambaran kehidupan manusia dan kehidupan itu sendiri merupakan suatu kenyataan sosial yang terjadi di lingkungan masyarakat. Masalah sosial yang terdapat dalam sebuah karya sastra merupakan reaksi dan tanggapan pengarang terhadap berbagai kenyataan sosial yang terjadi ditengah masyarakat. Karya sastra merupakan media untuk mengungkapkan pikiran-pikiran pengarang (Rosyanti, 2017:182). Hal ini digambarkan oleh pengarang dalam sebuah karya sastra seperti novel. Novel memiliki karakteristik permasalahan yang luas dan kompleks dibandingkan dengan karya sastra lainnya. Novel menceritakan perjalanan kehidupan seseorang yang menjadi tokoh pusat perhatian ketika membaca karya sastra tersebut. Tokoh utama merupakan tokoh yang menjadi pusat perhatian ketika membaca karya sastra. Segala yang berhubungan dengan karya sastra menjadi daya tarik pembaca, salah satu yang menarik mengenai tokoh utama adalah perilakunya.

Pengarang melalui penceritaan mengisahkan sifat-sifat tokoh, hasrat, perilaku, dan perasaannya. Hal ini karena pengarang ingin mengangkat persoalan kehidupan manusia yang beragam sifat dan karakternya. Sudjiman (1998:53) mengatakan bahwa novel adalah prosa rekaan yang menyuguhkan tokoh dan menampilkan serangkaian peristiwa serta latar secara tersusun. Novel sebagai karya imajinatif mengungkapkan aspek-aspek kemanusiaan yang mendalam dan menyajikannya secara halus. Novel tidak hanya sebagai alat hiburan, tetapi juga sebagai bentuk seni yang mempelajari dan meneliti segi-segi kehidupan dan nilai-nilai baik buruk (moral) dalam kehidupan ini dan mengarahkan pembaca tentang budi pekerti yang luhur.

Percakapan dalam novel harus sesuai dengan konteks pemakaiannya agar percakapan tersebut mirip dengan situasi nyata penggunaan bahasa, dengan demikian bentuk percapakan dalam sastra bersifat pragmatik. Bersifat pragmatik dikarenakan dalam berinteraksi seseorang dituntut bukan hanya memahami unsur-unsur bahasa, melainkan juga memahami unsur-unsur diluar bahasa tersebut yaitu konteks tuturan, (Putri:109). Tindak tutur terjadi dalam suatu peristiwa tutur. Tindak tutur dapat ditemukan pada karya sastra berbentuk prosa, salah satunya adalah novel (Fitriah dan Siti:52). Dalam tindak tutur dilihat dari makna atau arti tindakan dalam tuturannya. Sumbangan terbesar Austin dalam teori tindak tutur adalah pembedaan tindak tutur lokusi, ilokusi, dan perlokusi. Menurut Austin (dalam Umaroh:25) setiap kali penutur berujar, dia melakukan tiga tindakan secara bersamaan yaitu lokusi, ilokusi, dan perlokusi.

Tindak lokusi adalah konsep yang berkaitan dengan proposisi kalimat-kalimat tuturan, dalam hal ini dipandang sebagai satu satuan yang terdiri dari dua unsur yaitu subjek/topik dan predikat/perintah. Tindak tutur lokusi juga disebut the act of saying something yaitu menghasilkan ujaran dengan makna dan referensi tertentu. Sedangkan tindak ilokusi adalah tindak tutur yang biasanya diidentifikasikan dengan kalimat performatif yang eksplisit. Tindak tutur ilokusi adalah tindak tutur yang mengandung maksud dan fungsi atau daya ujar. Tindak tutur ilokusi dapat diidentifikasikan sebagai tindak tutur yang berfungsi untuk menginformasikan sesuatu dan melakukan sesuatu serta mengandung maksud dan daya tuturan. Selanjutnya, tindak tutur perlokusi adalah sebuah tuturan yang mempunyai efek atau daya pengaruh. Efek itu dapat ditimbulkan oleh penutur secara disengaja atau tidak disengaja. Tuturan ini mengandung daya pengaruh agar manusia mawas diri dengan apa yang telah dilakukan pada alam (Oktavia:3). 
Penelitian ini secara khusus meneliti tentang penggunaan bahasa terutama tindak tutur lokusi, ilokusi, dan perlokusi dalam novel Surat Kecil Untuk Tuhan Karya Agnes Davonar. Tindak tutur sebagai wujud peristiwa komunikasi bukanlah peristiwa yang terjadi dengan sendirinya, melainkan mempunyai fungsi, mengandung maksud, dan tujuan tertentu serta dapat menimbulkan pengaruh atau akibat pada mitra tutur.

Komunikasi dengan bahasa membuat setiap orang dapat menyesuaikan diri dengan lingkungannya. Dengan bahasa pula orang dapat mempelajari kebiasaan, adat istiadat, kebudayaan, dan latar belakang peserta komunikasi masing-masing. Penelitianpenelitian tindak tutur lokusi, ilokusi, dan perlokusi yang sudah dilakukan sebagian besar menggunakan objek penelitian berupa tuturan lisan, sehingga penulis berinisiatif meneliti tuturan lokusi, ilokusi, perlokusi dalam wana tulis yang menyertakan tuturan percakapan yang konktret seperti dalam novel Surat Kecil untuk Tuhan Karya Agnes Davonar. Novel ini mempunyai gagasan yang menarik untuk dikaji dan bila dilihat dari segi penceritaannya novel Surat Kecil untuk Tuhan Karya Agnes Davonar relevan dengan kehidupan moral keluarga, masyarakat yaitu menampilkan tekat yang ada dalam diri seorang gadis yang sedang menantang sakit kanker.

Adapun penelitian sebelumnya yang relevan dengan penelitian ini dilakukan oleh Handayani (2017) yang mengangkat judul Jenis Efek Dominasi Tuturan Lokusi, Ilokusi, dan Perlokusi dalam wacana AA Gym. Penelitian ini sama-sama memiliki persamaan yaitu menggunakan pendekatan stilistika. Namun yang dilakukan oleh Handayani menggunakan wacana lisan (dakwah AA Gym) sebagai sumber data yang dikaji sedangkan penelitian ini menggunakan wacana sastra novel.

Tujuan penelitian ini adalah mendeskripsikan bentuk tindak tutur lokusi pada Novel Surat Kecil untuk Tuhan Karya Agnes Davonar, (2) mendeskripsikan bentuk tindak tutur ilokusi pada Novel Surat Kecil untu Tuhan Karya Agnes Davonar, (3) mendeskripsikan bentuk tindak tutur perlokusi pada Novel Surat Kecil untuk Tuhan Karya Agus Davonar.

\section{METODE}

Jenis penelitian ini adalah penelitian deskriptif kualitatif karena sesuai dengan objek dan tujuan yang ingin dicapai oleh peneliti. Moleong (2007:6) mengartikan kualitatif sebagai suatu jenis penelitian yang bermaksud untuk memahami fenomena tentang apa yang dialami subjek penelitian secara holistik dan dengan cara deskripsi dalam bentuk kata-kata atau bahasa pada suatu konteks yang alamiah. Data penelitian ini adalah data yang berwujud kata-kata, ungkapan, kalimat yang terdapat dalam novel Surat Kecil untuk Tuhan Karya Agnes Davonar. Sumber data dalam penelitian ini adalah sumber data kepustakaan yaitu berupa buku, transkrip, majalah, dan lain-lain. Hal ini sejalan dengan perincian sebagai berikut: 1) sumber data primer, yaitu sumber data asli, sumber tangan pertama peneliti, yaitu berupa novel Surat Kecil untuk Tuhan, tahun terbitan pertama 2012, Gramedia Jakarta, dengan tebal halaman 425 halaman yang terdiri dari 37 sub judul. (2) sumber data sekunder, merupakan sumber data kedua. Sumber data sekunder yang digunakan dalam penelitian ini yaitu buku-buku acuan (pengantar kajian sastra), hasil penelitian yang berhubungan dengan permasalahan yang menjadi objek penelitian, artikel, dan sumber data dari tangan kedua (atau tangan yang kesekian), yang bagi peneliti tidak mungkin berisi data yang seasli sumber data primer.

Objek penelitian dalam novel Surat Kecil untuk Tuhan Karya Agnes Davonar mengkaji sosiolinguistik tindak tutur lokusi, ilokusi, dan perlokusi. Teknik pengumpulan data dalam penelitian ini menggunakan teknik 
kepustakaan (membaca, menyimak, dan mencatat). Teknik catat dilakukan dengan mencatat secara teliti terhadap data primer yakni novel Surat Kecil untuk Tuhan sebagai berikut: (1) pembacaan secara intensif terhadap sumber data yang mengacu pada objek penelitian yaitu membaca novel Surat Kecil untuk Tuhan karya Agnes Davonar, (2) menyimak dengan baik seluruh isi cerita, dan (3) melakukan pencatatan pada data yang diperoleh dari referensi dan penelitian sebelumnya sesuai data penelitian.

Teknik validasi data dalam penelitian ini digunakan teknik trianggulasi yaitu teknik yang didasari pola pikir fenomenologi yang bersifat multipersfektif, artinya untuk menarik simpulan yang baik diperlukan tidak hanya satu cara pandang. Triangulasi data yang digunakan yaitu triangulasi teoretis, yaitu peneliti menggunakan persfektif lebih dari satu teori dalam membahas permasalahan yang dikaji. Dalam penelitian ini menggunakan beberapa persfektif teori, yaitu teori sastra (unsur ekstrinsik, yakni aspek sosial dan sosiolinguistik pada novel.

Teknik analisis data dalam penelitian ini menggunakan teknik analisis data secara dialektika yang dilakukan dengan cara menghubungkan unsur-unsur yang ada dalam novel dengan mengintegrasikan kedalam suatu kesatuan makna. Goldman (dalam Faruk, 1999:20) mengungkapkan bahwa sudut pandang dialektika tidak pernah ada titik awal yang secara mutlak sahih, tidak ada persoalan secara final pasti terpecahkan. Adapun langkah-langkah yang digunakan dalam menganalisis data adalah: menganalisis novel Surat Kecil untuk Tuhan dengan menggunakan analisis struktural. Analisis struktural dilakukan dengan membaca dan memahami kembali data yang diperoleh. Selanjutnya, mengelompokkan teks-teks yang terdapat dalam novel Surat Kecil untuk Tuhan yang mengandung unsur tema, tokoh, alur, dan latar, (2) Analisis dengan tinjauan sosiologi sastra dilakukan dengan membaca dan memahami kembali data yang diperoleh. Selanjutnya, mengelompokkan teks-teks yang mengandung aspek sosial yang ada dalam novel Surat Kecil untuk Tuhan Karya Agnes Davonar.

\section{HASIL DAN DISKUSI}

\section{Tindak Tutur Lokusi}

Tindak tutur merupakan gejala individual bersifat psikologis dan keberlangsungannya ditentukan oleh kemampuan bahasa si penutur dalam menghadapi situasi tertentu. Tindak tutur lokusi adalah tindak tutur yang mengandung makna literal yang berhubungan dengan suhu udara di tempat tersebut, yang mengendung maksud berkaitan dengan siapa, bertutur kepada siapa, kapan, dan di mana. Tindak tutur itu dilakukan biasanya diidentifikasikan dengan kalimat performatif yang eksplisit. Seperti pada kutipan di bawah ini:

1. Selamat ya, Pak!! Anak Bapak masuk rangking 10 besar di kelas (diucapkan oleh wali kelas Keke kepada orang tua Keke saat pengambilan rapor). Skut Hlmn:8.

Dari kutipan tersebut merupakan kalimat berita, kalimat berita tersebut berfungsi untuk memberikan sesuatu pada penutur.

2. Keke anak yang pandai, (diucapkan oleh wali kelas kepada orang tua Keke, Kami adalah geng yang selalu bersama-sama) Skut Hlmn:15)

Kutipan tersebut merupakan kalimat pernyataan.

3. Upacara itu berakhir pada pukul) 7.45 pagi. (Skut Hlmn:9)

Kalimat berita performatif.

4. Di kelas kami ada satu geng lain yang diketahui oleh Angel (Skut hlmn:15)

Kalimat berita mengandung eksplisit.

5. Kemoterapi adalah cara umum mengahabisi sel kanker yang terjadi pada tubuh manusia.

Mengandung kalimat pernyataan.

6. Andi datang padaku dengan senyum yang tak bisa ku tolak (Skut hlmn:72) 
Kalimat berita.

7. Besarnya pembengkakan di wajahku mulai berkurang walau hanya beberapa cm saja.

Kalimat berita yang mengandung eksplisit.

8. Permusuhan itu sudah selesai, sekarang kita berteman (Skut hlmn:82)

Kalimat pernyataan mengandung eksplisit.

9. Aku masih ingin mengatakan beberapa hal, namun suaraku mulai hilang dari mulutku. (Skut hlmn:84)

Kalimat pernyataan mengandung eksplisit.

Dari beberapa penuturan tersebut merupakan kalimat berita. Kalimat berita tersebut berfungsi untuk memberitahukan sesuatu pada penutur, sehingga mitra tutur bisa mengerti apa yang disampaikan oleh penutur.

\section{Tindak Tutur Ilokusi}

Tindak tutur ilokusi adalah suatu tindakan dengan mengatakan sesuatu. Pada tindak tutur ilokusi, penutur yang menyatakan sesuatu dengan menggunakan suatu daya yang khas yang membuat si penutur bertindak sesuai dengan apa yang dituturkannya. Tindakan ini mengandung makna yang berhubungan dengan fungsi sosial yang diidentifikasikan dengan kalimat performatif yang eksplisit biasanya berkenan dengan permohonan, perizinan, mengucapkan terima kasih, menyuruh, menawarkan, dan menjanjikan, seperti pada kutipan di bawah ini:

1. Gimana Keke? Sakit ngga rasanya? Coba kamu mimta Bibi kasih tetes mata. (mengandung kalimat meyuruh) Skut hlmn:31.

2. Kalau pulang sekolah keadaan masih sama, lebih baik kita ke Dokter Adi

(kalimat menawarkan) seorang ayah menawarkan Keke. Skut hlmn:31.

3. Ya, kalau Keke sakit jangan ikut, entar tambah parah loh! (kalimat menawar).

4. "Tuhan... andai bisa Aku kembali, aku tidak ingin ada tangisan di dunia ini"

(kalimat permohonan) Skut hlmn. 198.

5. "Tuhan...izinkanlah rambutku kembali tumbuh, agar Aku bisa menjadi wanita seutuhnya.

(kalimat permohonan) Skut hlmn:198

\section{Tindak Tutur Perlokusi}

Tindak tutur perlokusi adalah tuturan yang menghasilkan efek atau hasil, yaitu efek yang ditimbulkan oleh ungkapan itu pada pendengar, sesuai dengan situasi dan kondisi pengucapan kalimat itu. Tanggapan itu tidak hanya berbentuk kata-kata, tetapi juga berbentuk tindakan atau perbuatan efek atau daya pengaruh yang disengaja atau tidak disengaja. Pengujaran dimaksudkan untuk mempengaruhi mitra tutur. Seperti kutipan di bawah ini:

"Ayah, Aku datang bulan, ujarku tersipu malu. Ayah hanya tersenyum seperti ingin menahan tawa, lalu Ayah harus bagaimana? Tanya Ayahku baik. (Skut hlmn:19)

"Wah Kak Kiki jadi lebih keren loh jadi kayak santri baja hitam hehehe.. (Tuturan ini diujarkan Keke ketika melihat Kiki sedang berkacamata hitam karena sakit mata) Skut hlmn:27.

Jangan-jangan kamu kena tumor!!! (ujar ibu itu spontan. Kata-kata itu mulai menghiasiku, dan aku mulai mengingat penyakit ini) Skut hlmn:57.

Keke... sampai kapan pun kamu adalah Keke yang Andi kenal, Andi tak pernah berpikir wajah Keke seperti apa, yang Andi suka dari Keke adalah sifat Keke. (kata ini diucapkan Andi ketika Keke malu dengan keadaan wajahnya yang bengkak.

Selama ada Ayah di sisi Keke rasa sakit akan menjadi rasa gatal. Hehehe... (diucapkan Keke ketika melihat Ayahnya panik akan menjalani kemoterapi).

Kalau saja nasib Keke seperti cewek difilm tentang sepasang kekasih yang berpisah karena 
salah satu diantara mereka meninggal karena kanker... Andi gimana?? (diucapkan Keke kepada pacar Keke setelah melihat film tentang sepasang kekasih yang berpisah karena diantaranya meninggal karena kanker) Skut hlmn:73.

Keke.. kita ini sedang diuji.. Keke harus sabar dan Keke harus ingat bahwa sesudah kesulitan pasti ada kemudahan (Tuturan ini diucapkan Ayah Keke ketika melihat Keke sedang gelisah menatap scan foto yang hasilnya menunjukkan ada kanker ditubuhnya) Skut hlmn:83.

Aku tidur selama 3 hari doang kan, kemarin Aku tidur kayaknya hari Senin yaa (tuturan inni diucapkan Keke ketika melihat orang-orang di sekitar panik karena ia pingsan selama tiga hari). Skut hlmn:82.

Dari sekian kalimat tersebut penutur mempunyai sifat memengaruhi mitra tutur.

Berdasarkan dari hasil penelitian tentang tindak tutur kata yaitu tindak tutur lokusi, ilokusi, dan perlokusi pada novel Surat Kecil untuk Tuhan Karya Agnes Davonar, dapat diklasifikasikan bahwa lokusi berjumlah 9, ilokusi berjumlah 5, dan perlokusi berjumlah 8. Hasil penelitian tersebut menunjukkan bahwa tindak tutur lokusi paling mendominasi yaitu tindak tutur yang menyatakan sesuatu dalam kata. Kemudian, tindak tutur perlokusi yang gaya kepekaan batinnya (intunisi) menonjol. Selanjutnya, tindak tutur ilokusi yang merupakan tindak tutur yang biasanya diidentifikasikan kalimat performatif yang eksplisit. Tindak tutur ilokusi ini biasanya berkenaan dengan pemberian izin, mengucapkan terima kasih, menyuruh, dan menawarkan. Hal tersebut sangat relevan dengan kajian stilistika dan novel Surat Kecil untuk Tuhan karena dalam novel tersebut menceritakan tentang kisah seorang gadis yang terserang penyakit kanker. Gadis tersebut memiliki sifat yang tegas, kuat, tegar, dan penyabar. Juga menceritakan tentang pengorbanan seorang kakak untuk adiknya.
Tentu saja dengan menggunakan kajian stilistika kita dapat mengetahui kepribadian dan hal-hal apa saja yang dialami dan dirasakan oleh tokoh Keke dalam novel Surat Kecil untuk Tuhan.

\section{KESIMPULAN}

Simpulan penelitian ini, yaitu tindak tutur lokusi pada novel Surat Kecil untu Tuhan Karya Agnes Davonar berjumlah 9. Tindak tutur ini paling mendominasi yaitu tindak tutur yang menyatakan sesuatu dalam berkata.

Tindak tutur ilokusi yang merupakan tindak tutur yang biasanya diidentifikasikan kalimat performatif yang eksplisit. Tindak tutur ilokusi ini biasanya berkenaan dengan pemberian izin, mengucapkan terima kasih, menyuruh, dan menawarkan. Tindak tutur ilokusi dalam novel Surat Kecil untu Tuhan Karya Agnes Davonar berjumlah 5.

Tindak tutur perlokusi pada novel Surat Kecil untuk Tuhan Karya Agnes Davonar yang menghasilkan efek atau hasil, yakni efek yang ditimbulkan oleh ungkapan itu pada pendengar, sesuai dengan situasi dan kondisi pengucapan kalimat itu berjumlah 8 .

\section{REFERENSI}

Damono, Sapardi Djoko. 1984. Sosiologi Sastra Sebuah Pengantar Ringkas. Jakarta, Pusat Pembinaan dan Pengembangan Bahasa.

Faruk. 1999. Pengantar Sosiologi Sastra. Yogyakarta, Pustaka Pelajar.

Fitriah dan Siti. 2017. Analisis Tindak Tutur dalam Novel Marwah di Ujung Bara Karya R. H. Fitriadi, 5 (1), 108-122.

Moleong, Lexy. 2007. Metodologi Penelitian Kualitatif. Bandung.

Oktavia, Wahyu. (2019). Tindak Tutur dalam Album Lirik Lagu Iwan Fals: Relevansinya Terhadap Pembentukan Karakter, 2 (2), 110. 
Putri.,Dian.,\& Suryadi. 2019. Tindak Tutur

Direktif pada Novel Bidadari-bidadari Surga

Karya Tere Liye, 3 (1), 108-122.

Rosyanti, Sinta. 2017. Nilai Moral dalam Novel

Surat Kecil untuk Tuhan Karya Agnes

Davonar, 1 (2), 182-190.

Sudjiman, Panuti. 1998. Memahami Cerita

Rekaan. Jakarta: UI Press.

Umaroh, Liya dan Neni, Kurniawati. 2017.

Dominasi Lokusi dan Perlokusi dalam

Transaksi Jual Beli, 7 (1), 21-34. 